\title{
Health Professional Students' Perceptions and Experiences of Remote Learning During the COVID-19 Pandemic
}

\author{
Fatmah Almoayad \\ Department of Health Sciences, College of Health and Rehabilitation Sciences \\ Princess Nourah Bint Abdulrahman University, Riyadh, Saudi Arabia \\ https://orcid.org/0000-0002-8424-5229
}

Afrah Almuwais

Department of Rehabilitation Sciences, College of Health and Rehabilitation Sciences Princess Nourah Bint Abdulrahman University, Riyadh, Saudi Arabia https://orcid.org/0000-0002-2774-868X

\section{Samiah F. Alqabbani}

Department of Rehabilitation Sciences, College of Health and Rehabilitation Sciences Princess Nourah Bint Abdulrahman University, Riyadh, Saudi Arabia https:// orcid.org/0000-0003-4495-5047

Nada Benajiba*
Department of Health Sciences, College of Health and Rehabilitation Sciences
Department of Basic Health Sciences, Deanship of Preparatory Year
Princess Nourah Bint Abdulrahman University,Riyadh, Saudi Arabia
https:// orcid.org/0000-0002-5533-7626

Abstract. This research aims to investigate the learning experiences and anxiety levels of students attending the College of Health and Rehabilitation Sciences (CHRS) at Princess Nourah bint Abdulrahman University (PNU), Saudi Arabia, during the sudden shift to virtual learning in response to COVID-19. A cross-sectional descriptive study was conducted among CHRS students $(N=254)$. Data was collected using an online questionnaire. Pearson's correlation coefficient was used to investigate the relationships between student perceptions of responsibility and independence in their learning during emergency remote teaching (ERT), the impact of ERT on learning goal achievement, and student anxiety levels. Results showed that $66.5 \%$ of participants scored moderate in their perceptions of independence and responsibility in their learning experiences. In addition, $54.3 \%$ of the students achieved their learning goals. Moreover, $20.9 \%$ of students reported that they had

\footnotetext{
" Corresponding author: Nada Benajiba; Email: benajibanada@gmail.com
} 
not experienced anxiety, while $24.4 \%$ had experienced severe anxiety. There was a significant negative correlation between student anxiety levels during ERT and their perceptions of responsibility and independence in learning $(r=-0.30, \mathrm{p}<0.001)$. In conclusion, student anxiety levels during the sudden shift to ERT moderately influenced student perceptions of independence and responsibility in their learning as well as learning goal achievement. Further studies are needed to explore the types of assistance to provide to students to improve the learning process during the current COVID-19 pandemic and similar circumstances where ERT is imposed.

Keywords: Emergency remote teaching; Remote learning; Health professional students; COVID-19 pandemic

\section{Introduction}

E-learning refers to education that is delivered using technology either fully or partially independent from fixed time and space (Hawkins \& Oblinger, 2005). Elearning was established in the late 1990s and has since been gradually integrated into higher education (Al-Asmari \& Khan, 2014; Hubackova, 2015). In 2005, higher education was expected to evolve progressively from in-person to online, leading to a revolutionary transformation (Hiltz \& Turoff, 2005). E-learning is becoming an essential part of health professional education: many educational institutions have incorporated it into their learning strategies (Ellaway \& Masters, 2008). In Saudi Arabia, higher institutions started adopting e-learning at the beginning of the $21^{\text {st }}$ century (Al-Asmari \& Khan, 2014). Since then, the Saudi Ministry of Education has established the National Centre for e-Learning and nearly every university in Saudi Arabia has created an e-learning unit or department (AlShehri, 2010). In addition, allied health colleges in Saudi universities also incorporated e-learning into their curriculums to create blended learning and not as complete e-learning (Sajid et al., 2016; Zakaria, Jamal, Bisht \& Koppel, 2013). However, in March 2020, the Saudi Ministry of Education imposed emergency remote teaching (ERT) on all educational institutions across the country (MOE, 2020). By definition, ERT is

'a temporary shift of instructional delivery to an alternate delivery mode due to crisis circumstances' (Hodges, Moore, Lockee, Trust \& Bond, 2020).

It was used as a preventive measure to limit the spread of COVID-19 and keep both staff and students safe. ERT was part of the anticipatory preventive and precautionary measures taken by the Saudi government, which also included social distancing and complete lockdown (SPA, 2020). The College of Health and Rehabilitation Sciences (CHRS) at Princess Nourah bint Abdulrahman University (PNU) has 13 different allied health profession specialisations (PNU, 2020). Similar to other allied health colleges at PNU, the CHRS was affected in several ways by the sudden implementation of ERT. In particular, its practical and clinical training courses were cancelled; these courses provide students with hands-on experience to master clinical skills through clinical training in different clinical settings, practical training, and roleplay simulation. As a replacement, students were provided with videos and case study reports. Albarrak (2011) demonstrated 
that e-learning training alternatives, such as virtual patients, videos, and animations, are common and effective in health profession education. However, students do not perceive them as sufficient in medical education and prefer to use them as complementary resources.

Students around the world were concerned about the sudden shift to ERT - it caused psychological distress and anxiety (Gallagher \& Schleyer, 2020; OdriozolaGonzález, Planchuelo-Gómez, Irurtia \& de Luis-García, 2020; Zhai \& Du, 2020). The psychological impact was caused by many factors. A study conducted among university students in China showed that students experienced feelings of frustration, anxiety, and betrayal as a result of the loneliness and loss of social connections, shelter, and homelike environment. These feelings were further amplified among students who stopped receiving mental health support from their universities which could increase the negative consequences of their mental health conditions (Zhai \& Du, 2020). Likewise, university closure had a moderate to severe impact on $50 \%$ of students' mental health at a Spanish university (Odriozola-González et al., 2020). In the United States, feelings of anxiety were exacerbated among health professional students who served on the front line during the COVID-19 pandemic as part of their clinical training (Gallagher \& Schleyer, 2020). The sudden implementation of ERT also caused tension to rise due to the new technologies deployed in teaching. In addition, e-assessments became an important component of remote teaching, which is usually challenging for both students and instructors (Ellaway \& Masters, 2008).

Aside from the seemingly inevitable psychological effects of ERT, e-learning has been reported to have several benefits: it helps support student autonomy, accommodates different learning styles, motivates student-teacher interaction, and provides flexibility and accessibility (Algahtani, 2011). Autonomy refers to students taking responsibility for their own learning, which, according to Drew (2018), is an important characteristic of learning that facilitates learning goal achievement and learner development (Algahtani, 2011). However, poorly designed courses could hinder the learning process (Edwards \& McKinnell, 2007), which could be the problem in the sudden shift to e-learning. Therefore, realistic expectations should be set and training should be provided to instructors. During its ERT period, PNU invested a great deal of time and effort to ensure that highquality teaching processes and assessments with minimal issues were provided to instructors and students. It focused on providing support and training, ensuring that not only were learning materials provided through learning management systems, such as Blackboard, but also to encourage flexible learning environments and improve communication and interactions between students and instructors.

Over the years, studies have reported inconclusive findings on the effectiveness of e-learning (Algahtani, 2011). During these discussions, it is crucial to consider the perspectives of both students and instructors as well as the learning context (Khan, 2005). Researchers should also clarify which aspects of effectiveness they are assessing and whether they are focusing on accomplishments of learning goals or learning perspectives (Algahtani, 2011). Moreover, George et al. (2014) 
evaluated the effectiveness of e-learning for students from five different health professions and found that it was as effective as or superior to in-person learning. Consequently, they recommended the adoption of e-learning in a variety of contexts, particularly where there was a shortage of faculty members or resources. While e-learning had a positive impact on the knowledge, attitudes, and satisfaction of health profession students (George et al., 2014; Haslerud, Tulipan, Gray Jr \& Biermann, 2017), its effectiveness in practical skills development was not demonstrated (George et al., 2014; Ngan, Tang, Chan, Chen \& Tang, 2018). For example, when comparing a group performing hands-on lab work to a group performing simulation-based lab work remotely, (Corter, Esche, Chassapis, Ma \& Nickerson, 2011) found that while the simulation group achieved better results, the hands-on group had a higher motivation. Their study concluded that properly designed and coordinated remote learning could improve learning goal achievement (Corter et al., 2011). Tinio (as cited in Edwards and McKinnell (2007) emphasised that when e-learning is carefully designed and implemented, it can empower students in terms of skills development as well as knowledge acquisition. Also, some positive outcomes were associated with proper e-learning, including improved student-instructor and student-student interactions, improved active and independent learning, improved time management, and the ability to accommodate different learning styles (Edwards \& McKinnell, 2007), showing that students are taking on a higher level of responsibility for their learning.

Edwards and McKinnell (2007) identified five crucial areas in e-learning activities: planning and design, teaching or providing learning support, student assessment and feedback, facilitating effective learning environments and guidance, and research and professional activities. PNU has addressed the first four activities; this study was conducted to address the fifth by investigating learning from the perspective of students attending CHRS. This research investigates students' perspectives of learning and anxiety levels during the sudden shift to ERT in response to the COVID-19 pandemic at the CHRS. Our objectives were to (1) assess student perceptions of responsibility in learning during ERT, (2) assess student perceptions of the impact of ERT on learning goal achievement, (3) investigate student anxiety levels during ERT, and (4) evaluate the correlation between students' perceptions of learning and anxiety levels. We hypothesised that the overall learning experience would be positive and anxiety levels would be high among students. The findings of this study will contribute to the literature by helping educational institutions better prepare online learning programmes during emergencies. It can also help develop appropriate plans to overcome possible challenges to strengthen the experience of e-learning.

\section{Methods}

\subsection{Study design and subjects}

This was a cross-sectional descriptive study. The study population included students from 13 different applied medical sciences and public health programmes at the CHRS at PNU. The study sample was calculated to be 251 of 720 students $(95 \% \mathrm{CI} ; p=0.5)$ attending the CHRS. A total of 54 students participated in the study. Data was collected in May 2020 using an electronic 
questionnaire distributed to students through the CHRS student mailing list. Students were recruited using the method of non-probability sampling for a known population. Students from all study levels were included. Preparatory year students and students who were not registered for the academic semester during which the study took place were excluded. Since a non-probability sampling was used, available primary data from participants was used in this research until the requested sample size $(\mathrm{N}=251)$ was reached This type of sampling was selected because it was the most convenient method to collect data during the COVID-19 pandemic lockdown. The study was conducted after obtaining ethical approval from the IRB committee at PNU (IRB Log Number: 200162). All recruited students gave their consent before taking part in the study. They were provided information about the study, including its objectives, voluntarily participation, anonymity, and confidentiality of data collected.

\subsection{Study instruments}

The questionnaire was developed using previous literature Ghenghesh, Croxford, Nagaty \& Abdelmageed, 2018; Uziak, Oladiran, Lorencowicz \& Becker, (2018) to suit the objectives of this study. It consists of the following four sections. Section 1 focuses on collecting sociodemographic and sample characteristics, including age, department, programme of study, level of study, and GPA. Section 2 measures student perceptions of responsibility in learning during ERT. Students answered six questions using a Likert scale (Likert, 1932). The questions focused on student responsibility and independence in their learning, student-instructor interactions, time management, and organisation. Participants were categorised into groups based on their scores: low (range: 6-14), moderate (range: 15-22), and high (range: 23-30). Section 3 assesses student perceptions of the impact of ERT on learning goal achievement and learning quality. It consisted of five questions that were answered using a Likert scale (Likert, 1932). The questions aimed to determine if ERT improved the quality of their education, enabled them to complete assignments faster and more efficiently, helped them better understand the subject material, helped them develop knowledge and skills and improved their motivation when learning. Students were categorised into three groups based on their scores: low (range: 5-11.6), moderate (range: 11.7-17.2), and high (range: 17.3-25). In Sections 2 and 3, total scores were used instead of the average scores for each item, as recommended by Warmbrod (2014). This was done because total scores have been reported to provide congruent interpretations of obtained results. Section 4 assesses student anxiety levels during ERT using the General Anxiety Disorder-7 (GAD-7) tool (Spitzer, Kroenke, Williams \& Löwe, 2006). It is a self-administered test that measures the severity of anxiety using seven questions. Each question gives a score from 0 (not at all) to 3 (nearly every day); total scores ranged from 0 to 21 . Respondents were categorised into groups based on their scores: no anxiety (range: 0-4), mild anxiety (range: 5-9), moderate anxiety (range: 10-14), and severe anxiety (15-21; (Spitzer et al., 2006).

\subsection{Validity and reliability}

All components of the research tool were tested for validity by six academic teachers involved in e-learning that were fluent in both English and Arabic. The tool was piloted with 24 CHRS students before it was shared online; no amendments were needed as students stated that the questions were clear and 
easily understood. The questionnaire's reliability was tested using Cronbach's a; coefficient values were $0.91,0.72$, and 0.82 for anxiety, responsibility, and goal achievement, respectively. This indicated a good internal consistency, as reported by Nunnally (1975). The questionnaire's feasibility was evaluated during the pilot study with $10 \%$ of the sample group; minor modifications were needed.

\subsection{Statistical analysis}

Data analysis was performed using SPSS software (version 22), and results were presented in terms of frequency and percentage. The Kolmogorov-Smirnov and Shapiro-Wilk tests were conducted; they showed that the data for anxiety and perceived learning had an approximately normal distribution. The Pearson correlation coefficient was applied to assess the correlation between different studied parameters. One-way ANOVA was used to assess the differences among the groups. Bonforroni post-hoc analysis was applied to determine which groups were significantly different $(p \leq 0.05)$.

\section{Results}

\subsection{General characteristics}

A total of 254 students attending the CHRS (mean age: $21.1 \pm 1.6$; mean GPA: 4.4 \pm 0.3 ) participated in the study. Students from the Rehabilitation Science Department and the Health Sciences Department account for $35.8 \%$ and $45.3 \%$ of the total sample, respectively, as they are the two largest departments at the CHRS (Table 1).

Table 1: General characteristics of the study population $(N=254)$

\begin{tabular}{|l|c|c|}
\hline Variable & $\boldsymbol{N}$ & $\mathbf{\%}$ \\
\hline Academic department & 91 & 35.8 \\
Rehabilitation Science & 115 & 45.3 \\
Health Sciences & 22 & 8.7 \\
Communication Sciences & 26 & 10.2 \\
Radiology Sciences & & \\
\hline Academic program & 59 & 23.2 \\
Doctor of Physiotherapy & 10 & 3.9 \\
Physiotherapy & 22 & 8.7 \\
Occupational Therapy & 27 & 10.6 \\
Epidemiology & 31 & 12.2 \\
Health Education & 36 & 14.2 \\
Clinical Nutrition & 21 & 8.3 \\
Clinical Psychology & 11 & 4.3 \\
Speech and Swallowing Disorders & 11 & 4.3 \\
Audiology and Balance & 13 & 5.1 \\
Nuclear Medicine Technology & 3 & 1.2 \\
Radiation Therapy & 10 & 3.9 \\
Diagnostic Imaging & & \\
\hline Level of study & 81 & 31.9 \\
Entry & 79 & 31.1 \\
Intermediate & 94 & 37 \\
Graduate &
\end{tabular}




\begin{tabular}{|l|c|c|}
\hline Grade point average (GPA) & & \\
Excellent (> 4.5) & 105 & 41.3 \\
Very Good (range: $3.75-4.5)$ & 128 & 50.4 \\
Good (range: 2.5-3.75) & 14 & 5.5 \\
Poor (<2.5) & 0 & 0.0 \\
\hline & Mean & SD \\
\hline Age (years) & 21.0 & \pm 1.6 \\
\hline
\end{tabular}

\subsection{Student independence, responsibility, goal achievement and anxiety}

The results in Table 2 show that $66.5 \%$ of participants had a moderate perception of their independence and responsibility in their learning, while $26 \%$ had a high perception. Learning goal achievement was high among $16.1 \%$ of participants and moderate for $54.3 \%$ of participants. Anxiety level results revealed that $20.9 \%$ had no anxiety and $24.4 \%$ had severe anxiety.

Table 2: Student scores for responsibility and independence in learning, learning goal achievement, and anxiety levels $(N=254)$

\begin{tabular}{|c|c|c|}
\hline Variable & $\mathbf{N}$ & $\%$ \\
\hline \multicolumn{3}{|l|}{ Independence and responsibility } \\
\hline Low (range: 6-14) & 19 & 7.5 \\
\hline Moderate (range: $15-22)$ & 169 & 66.5 \\
\hline High (range: 23-30) & 66 & 26.0 \\
\hline \multicolumn{3}{|l|}{ Goal achievement } \\
\hline Low (range: 5-11.6) & 75 & 29.5 \\
\hline Moderate (range: $11.7-17.2$ ) & 138 & 54.3 \\
\hline High (range: $17.3-25$ ) & 41 & 16.1 \\
\hline \multicolumn{3}{|l|}{ Anxiety levels } \\
\hline No anxiety (range: $0-4$ ) & 53 & 20.9 \\
\hline Low anxiety (range: 5-9) & 90 & 35.4 \\
\hline Moderate anxiety (range: 10-14) & 49 & 19.3 \\
\hline Severe anxiety (range: 15-21) & 62 & 24.4 \\
\hline
\end{tabular}

Student perceptions of responsibility and independence in their learning during ERT are presented in Figure 1. Roughly $67 \%$ of students selected the response 'Shifting to remote learning made me more responsible about my own learning'. Moreover, $74.8 \%$ selected 'Shifting to remote learning helped me to become an independent learner' and $71 \%$ selected 'Shifting to remote learning helped me to work at my own pace'. However, only 30\% selected 'Shifting to remote learning helped me manage my time more effectively'. 
Strongly agree $\square$ Agree $\square$ Neutral $\square$ Disagree $\square$ Strongly disagree

Shifting to remote learning helped me manage my time more effectively

Shifting to remote learning helped me to work at my own pace

Shifting to remote learning helped me to become an independent learner

Shifting to remote learning improved the interaction between me and the course instructor

Shifting to remote learning helped me to be better organized

Shifting to remote learning made me more responsible about my own learning

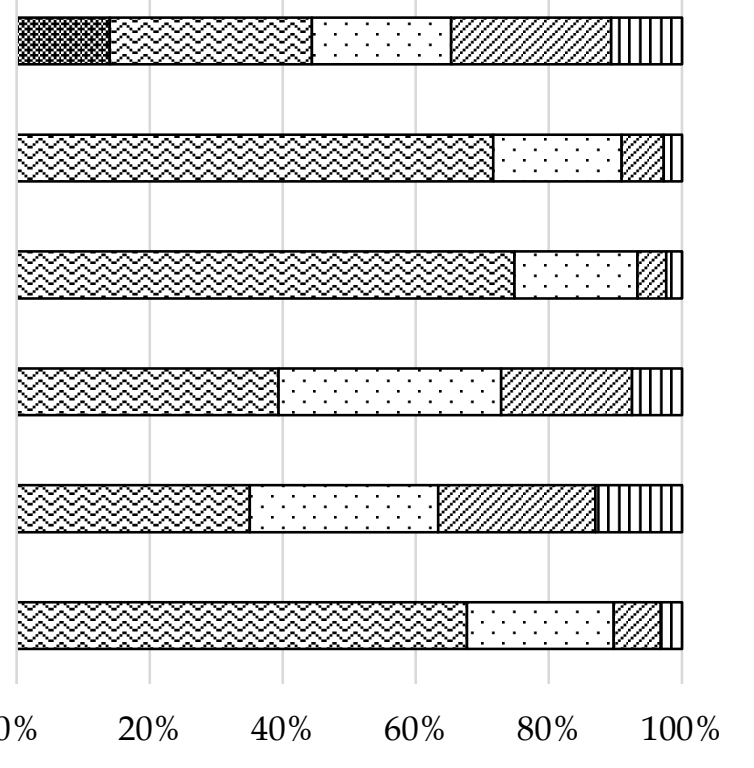

Figure 1: Student perceptions of responsibility and independence in their learning during $\operatorname{ERT}(N=254)$

In contrast, student agreement on the impact of ERT on learning goal achievement was lower. Only $54.3 \%$ selected the response 'Shifting to remote learning enabled me to accomplish assignments more quickly and efficiently', $13 \%$ selected 'Remote learning motivated better learning', and 26\% selected 'Remote learning helped in knowledge and skills development' (Figure 2). When assessing anxiety levels, we found that 'several days' had the highest selection rate for all questions, except 'Being so restless that it's hard to sit still', where $40 \%$ stated that they did not experience this at all.

圈Strongly agree $\quad$ Agree $\square$ Neutral $\bowtie$ Disagree $\square$ Strongly disagree

Remote learning motivated better learning

Remote learning helped in knowledge and skills development

Remote learning helped me understand the subject's material well

Shifting to remote learning enabled me to accomplish assignments more quickly and efficiently

Shifting to remote learning improved the quality of my studies

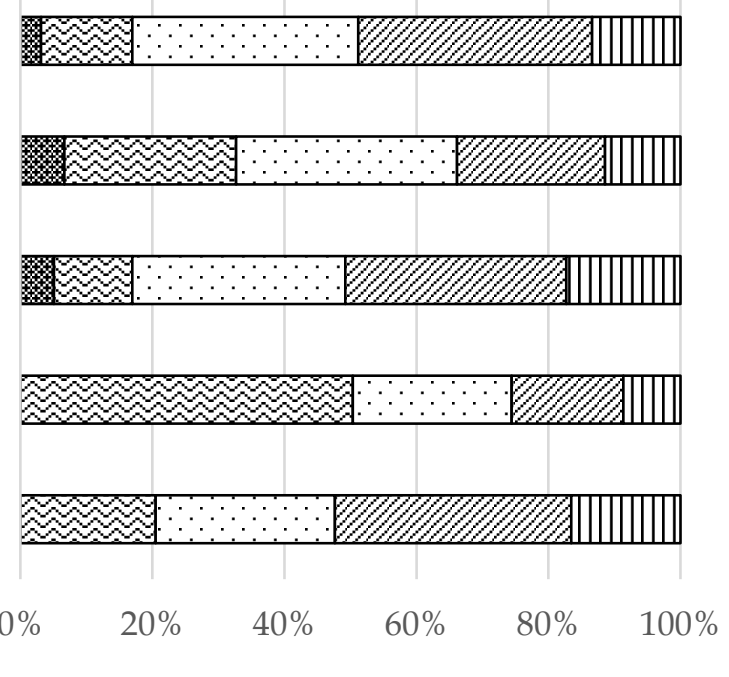

Figure 2: Impact of ERT on goal achievement $(N=254)$ 


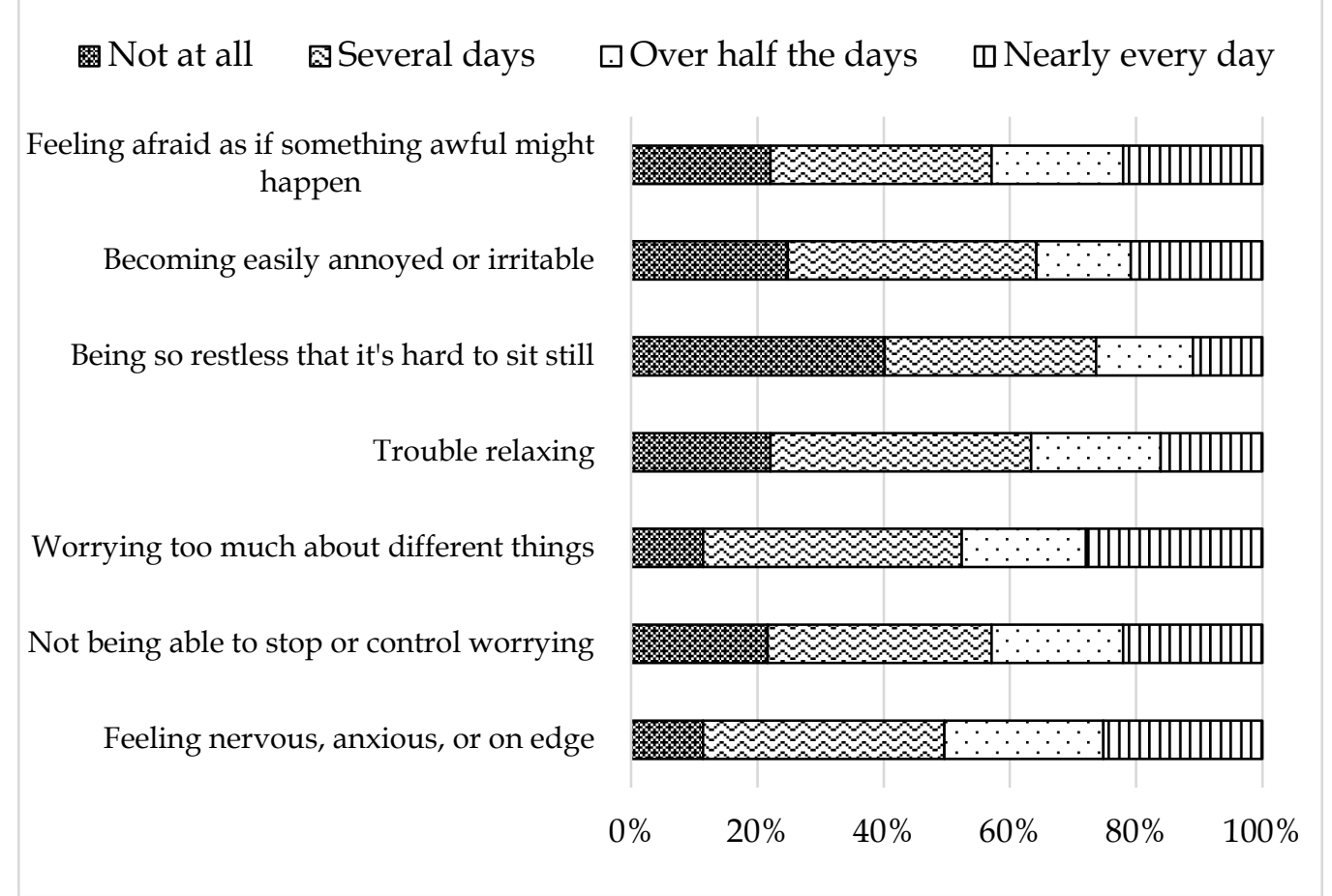

Figure 3: Student General Anxiety Disorder-7 scores $(N=254)$

3.3 Scores or independence and responsibility, goal achievement, and anxiety The score results indicated that students' levels of study significantly affected goal achievement and anxiety levels (see Table 3). There was a significant difference in mean GAD-7 score among the three levels $(p=0.024)$. Post-hoc analysis indicated that the mean anxiety level was significantly lower for students at the intermediate level compared to those in the entry level $(p=0.035)$. There was also a significant difference in mean learning goal achievement among the three study levels $(p=0.011)$, and the mean was higher for intermediate level students than for graduate level students $(p=0.008)$.

Table 3: Mean $( \pm$ SD) scores for independence and responsibility, goal achievement, and anxiety levels for study levels $(N=254)$

\begin{tabular}{|l|c|c|c|c|c|}
\cline { 2 - 6 } \multicolumn{1}{c|}{} & \multirow{2}{*}{ Range } & \multicolumn{4}{c|}{ Study level } \\
\cline { 3 - 6 } \multicolumn{1}{c|}{} & $\begin{array}{c}\text { Entry } \\
(\boldsymbol{n}=\mathbf{8 1})\end{array}$ & $\begin{array}{c}\text { Intermediate } \\
(\boldsymbol{n}=\mathbf{7 9})\end{array}$ & $\begin{array}{c}\text { Graduate } \\
(\boldsymbol{n}=\mathbf{9 4})\end{array}$ & $\boldsymbol{p}$-value \\
\hline Responsibility and independence & $6-30$ & $19.6 \pm 3.6$ & $20.4 \pm 3.7$ & $19.6 \pm 3.2$ & 0.283 \\
\hline Goal achievement & $5-25$ & $13.7 \pm 3.9$ & $14.7 \pm 4.1^{\mathrm{b}}$ & $12.9 \pm 3.6^{\mathrm{b}}$ & 0.011 \\
\hline Anxiety level & $0-21$ & $10.6 \pm 5.5^{\mathrm{c}}$ & $8.3 \pm 5.9^{\mathrm{c}}$ & $10.2 \pm 5.9$ & 0.024 \\
\hline
\end{tabular}

$\mathrm{SD}=$ Standard deviation. ANOVA was used to assess differences between scoring groups for each study level. Mean scores were compared using the Bonferroni post-hoc test. $a=$ ANOVA $p$-value. $b=$ Significant difference in mean goal achievement between students in the intermediate and graduate levels $(p=0.035) . c=$ Significant difference in mean anxiety levels between students in the intermediate and entry levels $(p=0.008)$. 
Table 4: Mean $( \pm$ SD) scores for independence and responsibility and goal achievement for different anxiety levels $(N=254)$

\begin{tabular}{|c|c|c|c|c|c|c|}
\hline & \multirow[b]{2}{*}{ Range } & \multicolumn{5}{|c|}{ Anxiety level } \\
\hline & & $\begin{array}{c}\text { None } \\
(n=53)\end{array}$ & $\begin{array}{c}\text { Low } \\
(n=90)\end{array}$ & $\begin{array}{c}\text { Moderate } \\
(n=49)\end{array}$ & $\begin{array}{l}\text { Severe } \\
(n=53)\end{array}$ & $p$-value \\
\hline $\begin{array}{l}\text { Responsibility and } \\
\text { independence }\end{array}$ & $6-30$ & $21.3 \pm 2.3^{b, c}$ & $20.3 \pm 3.6^{d}$ & $19.3 \pm 3.4$ & $18.4 \pm 3.8$ & $<0.001$ \\
\hline $\begin{array}{l}\text { Goal achievement } \\
\text { of goals }\end{array}$ & $5-25$ & $16.1 \pm 3.2^{b, c, c}$ & $13.9 \pm 3.7^{d}$ & $12.8 \pm 4.1$ & $12.1 \pm 3.8$ & $<0.001$ \\
\hline
\end{tabular}

$\mathrm{SD}=$ Standard deviation. ANOVA was used to assess differences between scoring groups for each study level. Mean scores were compared using the Bonferroni post-hoc test. a $=$ ANOVA $p$-value. $b=$ Significant difference between students with no anxiety and moderate anxiety $(p=0.025) . c=$ Significant difference between students with no anxiety and severe anxiety $(p<0.001) . d=$ Significant difference between students with low anxiety and severe anxiety $(p<0.001) . e=$ Significant difference between students with no anxiety and low anxiety $(p=0.007)$.

Mean student perception scores for independence and responsibility, as well as goal achievement, are sorted by anxiety level in Table 4 . There was a significant difference in mean independence and responsibility scores among the four anxiety levels $(p<0.001)$. Mean scores were significantly higher for students with no anxiety than moderate $(21.3 \pm 2.3$ vs. $19.3 \pm 3.4 ; p=0.025)$ and severe anxiety $(21.3 \pm 2.3$ vs. $18.4 \pm 3.8 ; p<0.001)$. They were also higher for students with low anxiety than severe anxiety $(20.3 \pm 3.6$ vs. $18.4 \pm 3.8 ; p<0.001)$. Differences in mean learning goal achievement were also significant for the four anxiety levels $(p<$ 0.001; see Table 4). Bonferroni post-hoc analysis revealed that mean scores were significantly higher in the no anxiety group compared to all other levels. In addition, there was a significant difference in mean learning goal achievement between the low and severe anxiety groups $(13.9 \pm 3.7$ vs. $12.1 \pm 3.8 ; p=0.019)$.

\subsection{Correlation between independence and responsibility, goal achievement, and anxiety level}

Table 5 summarises the correlation between each study variable. Pearson's $r$ revealed a strong positive correlation between student perceptions of independence and responsibility in their learning and learning goal achievement $(r=0.68 ; p<0.001)$. However, there was a moderate negative correlation between anxiety level and student perceptions of independence and responsibility $(r=$ $0.30 ; p<0.001)$ as well as learning goal achievement $(r=-0.36 ; p<0.001)$. GPA did not have a significant correlation with any variables (Table 5).

Table 5: Correlation between independence and responsibility, goal achievement, and student anxiety levels during ERT $(N=254)$

\begin{tabular}{|l|l|l|l|}
\cline { 2 - 4 } \multicolumn{1}{c|}{} & $\begin{array}{l}\text { Independence and } \\
\text { responsibility }\end{array}$ & $\begin{array}{l}\text { Goal } \\
\text { achievement }\end{array}$ & $\begin{array}{l}\text { Anxiety } \\
\text { level }\end{array}$ \\
\hline $\begin{array}{l}\text { Independence and } \\
\text { responsibility }\end{array}$ & 1 & $.68^{* *}$ & $-.30^{* *}$ \\
\hline Goal achievement & --- & 1 & $-.36^{* *}$ \\
\hline Anxiety level & --- & --- & 1 \\
\hline
\end{tabular}

Pearson's $r$ was used to calculate the correlation strength between each set of variables.

**Significant at $p<0.001$. 


\section{Discussion}

This study assessed the learning process from the CHRS students' point of view during the sudden shift to virtual learning in response to the COVID-19 pandemic, measuring aspects related to anxiety, achievement of learning goals and the perception of independence/responsibility toward their e-learning.

The findings of the study revealed that students considered the effect of the sudden shift to remote teaching on their responsibilities and their independence towards their learning to be high. Indeed, agreement on 'Shifting to remote learning helped me to become an independent learner' and 'Shifting to remote learning made me more responsible about my own learning' was reported as $74.8 \%$ and $67.7 \%$, respectively. Student recognition of responsibility towards learning is an important factor (Joo, Lim \& Kim, 2011). Ilic, Hart, Fiddes, Misso and Villanueva (2013) indicated that there was no difference in student competency between the blended learning and traditional dictation. However, Joo et al. (2011) reported that student recognition of their responsibilities in the elearning environment was a predictor of learning persistence and learning flow. Furthermore, the perception of achievement of learning goals was strongly related to the perception of independence in learning in this study. Yang and Cao (2013) concluded that self-regulation was related to learning achievement. In the learning context, self-regulation refers to the degree to which students engage in the learning process using metacognition and to proper motivation (Zimmerman \& Martinez-Pons, 1988). Moreover, it has also been demonstrated that achievement of learning goals was a predictor of successful learning (Yang \& Cao, 2013).

Motivation is a key element for students to engage in e-learning. Only $13.8 \%$ of the students participating in this study reported that shifting to ERT improved their motivation towards learning. However, a moderate achievement of goals was obtained by $54.3 \%$. Several studies have linked students' motivation to achievement of learning goals (Pekrun, 2006; Yang \& Cao, 2013). Although the percentage of students agreeing to the statement 'Remote learning motivated better learning' was not high, this did not reflect their overall perception regarding the accomplishment of learning goals. In fact, half of the students reported agreement on the statement 'Shifting to remote learning enabled me to accomplish assignments more quickly and efficiently'. Yang and Cao (2013) indicated that a task-approach goal was not influenced by intrinsic motivation. Student assessment is a major concern, and this may explain the higher level of accomplishment regardless of motivation, as students may have focussed on getting the task done and proceeding regardless of their sense of motivation.

In contrast, a substantial number of students in this study perceived e-learning as adversely affecting the quality of their knowledge and skill acquisition as well as their understanding of the subject material. In fact, it has been well demonstrated that knowledge acquisition is an essential factor for interpreting the success of an e-learning experience. Rodríguez-Ardura and Meseguer-Artola (2016) confirmed that students are more concerned about the quality of knowledge in e-learning than the quality of the learning management system itself. Some disadvantages of 
e-learning may contribute to the dissatisfaction of the students in relation to elearning effectiveness. It is highly recommended in e-learning strategy that students should have a high level of self-discipline, and they are expected to spend more time and effort understanding the subject material on their own.

Moreover, the minimal interaction and direct contact with instructors in the elearning environment has a considerable influence on student perception of effectiveness (Bouhnik \& Marcus, 2006). Muilenburg and Berge (2005) indicated that a lack of social interaction is a major barrier in terms of student perception of e-learning effectiveness. In our context, the shift towards e-learning was sudden and without prior planning, which may have increased student concerns for their education. The suspension of all practical and clinical training may also have contributed to student disagreement on the quality of their study. The alternatives provided for practical and clinical training may not have been enough to alleviate student concerns regarding their clinical-skill acquisition and may also be related to the higher levels of student anxiety. This study revealed the existence of a negative and significant correlation between the level of anxiety and the perception of learning effectiveness; the higher the anxiety, the lower the perception of learning effectiveness. You and Kang (2014) investigated the impact of emotions in the academic setting, including anxiety, on perceived academic control. They reported the existence of a significant relationship between anxiety and academic control. Perceived control is

'an individual's believed capacity to predict and influence events in their environment'. (Perry \& Smart, 1997, p. 12)

It is also considered an important predictor of achievement emotions (Pekrun, 2006) as well as academic motivation and performance (Perry, Hladkyj, Pekrun \& Pelletier, 2001). Conversely, anxiety is one of the most frequent emotions reported as a result of e-learning (Hara, 2000; Hara \& Kling, 2001; You, Kang \& Pahng, 2013). The current study assessed anxiety using GAD-7, while anxiety in the previous studies was part of a comprehensive questionnaire involving other academic emotions related to e-learning. However, higher anxiety levels had already been reported by college students in general (Beiter et al., 2015). Moreover, several studies indicated that anxiety is one of the most frequent emotions reported due to e-learning (Hara \& Kling, 2001). Additionally, concerns regarding the COVID-19 pandemic could be a contributing source to the overall anxiety reported by students (Cao et al., 2020; Liu, Liu \& Zhong, 2020).

The results showed that the perceived independence/responsibility of students towards their learning and their achievement of learning goals were significantly impacted by the level of anxiety. Perry et al. (2001) indicated that perceived academic control was affected by a student's anxiety. Additionally, students at the graduate and entry levels showed higher anxiety than those at the intermediate level. Similarly, Beiter et al. (2015) reported higher anxiety in students at higher levels. Furthermore, Moore, Madsen and Trans (2019) demonstrated high anxiety in first-year medical students. Consequently, the perception of achievement of learning goals and student responsibility were greater at intermediate levels, which could be influenced by anxiety. Cao et al. (2020) investigated anxiety levels 
in college students using GAD-7. They reported that anxiety in students during the COVID-19 pandemic impacted academic activities and could lead to delays in their learning. However, they reported lower anxiety levels compared to the levels obtained in this study, as only $0.9 \%$ of their subjects had severe anxiety. However, Saddik et al. (2020) investigated the anxiety level in relation to e-learning among university students using GAD-7. The percentages for the anxiety levels were similar to this study. They indicated that medical students had higher levels of anxiety before shifting to e-learning; interestingly, they demonstrated that the anxiety levels were lower after the introduction of e-learning when compared to non-medical students. Also, female participants in their study demonstrated higher anxiety levels compared to male participants. However, female participants demonstrated lower anxiety levels with the shift to ERT in response to the COVID-19 pandemic. Therefore, during a crisis that causes a shift to elearning, such as the COVID-19 pandemic or a similar emergency, educational institutions should support student mental health along with student learning.

\section{Conclusion}

Taken together, the findings of this study highlight the connection between anxiety levels and the perception of the learning experience during the sudden shift to virtual learning in response to the COVID-19 pandemic among healthprofession students in CHRS (PNU). Anxiety levels were significantly high, which could be considered a logical outcome of the ERT and the total lockdown in response to the COVID-19 pandemic. This anxiety had a moderate effect on the perception of both the independence and responsibility of students towards their learning as well as on their achievement of learning goals. Furthermore, as $24.4 \%$ of the students reported severe anxiety, it is recommended that there should be a plan to deliver both specific education and psychological support to help mitigate any potentially negative consequences on the learning process during the COVID19 pandemic. Findings can also be extrapolated to similar emergencies where ERT is imposed. Additionally, while e-learning is generally encouraged in the case of health-profession education, well-designed blended learning could be considered a preferable learning strategy to ensure the benefits of e-learning while accommodating clinical and practical training. However, further studies are needed to explore in depth the type of assistance that would improve the student learning experience during the current COVID-19 pandemic.

\section{Strengths and limitations}

The study instrument used for data collection was highly reliable, as demonstrated by good internal consistency: $\alpha=0.91$ for anxiety, $a=0.72$ for responsibility and $a=0.82$ for achieving goals. Moreover, the survey was conducted during the COVID-19 pandemic and hence represents precise insight from CHRS students in relation to their e-learning experience. Lastly, reviewing the literature, this study seems to be the first to focus on the learning process from the perspective of health-profession students at Saudi universities. Thus, evaluating this experience could bring valuable results and provide guidance for the decision-making process at CHRS concerning which aspects and components of learning should be prioritised to improve e-learning from a long-term 
perspective. However, due to the sudden shift, the research could not compare results to data pre-ERT.

The data was collected through a non-probability sampling for a known population; the inclusion criteria were clear and students belonged to the same college (CHRS), which indicates that this sampling procedure would have a reduced bias. Consequently, the findings of this research can be generalised beyond the study population.

Acknowledgments: This research was funded by the Deanship of Scientific Research at Princess Nourah bint Abdulrahman University through the Fast-track Research Funding Program.

Conflicts of interest/Competing interests: There are no conflicts of interest.

Ethics approval: Ethical approval from the Institutional Review Board/Ethics Committee at Princess Nourah Bint Abdulrahman University was obtained prior to conducting the study (IRB Log Number 20-0162).

Consent to participate: The consent to participate was displayed on the first page of the online questionnaire and included the objectives of the study. Participants were recruited voluntarily, and anonymity was maintained through all stages of the research. Participants were assured of the confidentiality of their data and that it would only be used for research purposes. Participants were informed that by answering the questionnaire they were giving their consent to participate in the study.

Author contributions: All the authors (Fatmah Almoayad, Afrah Almuwais, Samiah F. Alqabbani, and Nada Benajiba) did the following:

- made a substantial contribution to the design of the work and the acquisition and statistical analysis of the data;

- contributed significantly to the interpretation of the data and the drafting of the article;

- contributed in collating the supporting literature, adding to and improving the scientific merit of the study and revising the manuscript for English language grammar, syntax and flow as well as correct formatting;

- revised and approved the version to be published; and

- participated sufficiently in the work to take public responsibility for appropriate portions of the content.

\section{References}

Al-Asmari, A. M., \& Khan, M. S. R. (2014). E-learning in Saudi Arabia: Past, present and future. Near and Middle Eastern Journal of Research in Education, 2014(1), 2. https://doi.org/10.5339/nmejre.2014.2

Al-Shehri, A. M. (2010). E-learning in Saudi Arabia:'To E or not to E, that is the question'. Journal of family and community medicine, 17(3), 147. https:/ / doi.org/10.4103/13191683.74333 
Albarrak, A. (2011). E-learning in medical education and blended learning approach. learning, 13, 14-20. https:// doi.org/10.1111/j.1540-4609.2011.00325.x

Algahtani, A. (2011). Evaluating the E ectiveness of the E-learning Experience in Some Universities in Saudi Arabia from Male Students' Perceptions. (PhD), Durham University.

Beiter, R., Nash, R., McCrady, M., Rhoades, D., Linscomb, M., Clarahan, M., \& Sammut, S. (2015). The prevalence and correlates of depression, anxiety, and stress in a sample of college students. Journal of affective disorders, 173, 90-96. https://doi.org/10.1016/j.jad.2014.10.054

Bouhnik, D., \& Marcus, T. (2006). Interaction in distance-learning courses. Journal of the American Society for Information Science and Technology, 57(3), 299-305. https://doi.org/10.1002/asi.20277

Cao, W., Fang, Z., Hou, G., Han, M., Xu, X., Dong, J., \& Zheng, J. (2020). The psychological impact of the COVID-19 epidemic on college students in China. Psychiatry research, 287, 112934. https://doi.org/10.1016/j.psychres.2020.112934

Corter, J. E., Esche, S. K., Chassapis, C., Ma, J., \& Nickerson, J. V. (2011). Process and learning outcomes from remotely-operated, simulated, and hands-on student laboratories. Computers $\mathcal{E}$ Education, 57(3), 2054-2067. https://doi.org/10.1016/j.compedu.2011.04.009

Drew, S. (2018). The student skills: guide. London, UK: Routledge.

Edwards, A., \& McKinnell, S. (2007). Moving from dependence to independence: the application of e-learning in higher education. Learning, teaching and assessing in higher education: Developing reflective practice, 68.

Ellaway, R., \& Masters, K. (2008). AMEE Guide 32: e-Learning in medical education Part 1: Learning, teaching and assessment. Medical teacher, 30(5), 455-473. https://doi.org/10.1080/01421590802108331

Gallagher, T. H., \& Schleyer, A. M. (2020). "We Signed Up for This!" - student and trainee responses to the COVID-19 pandemic. New England Journal of Medicine, 25, e96. https://doi.org/10.1056/nejmp2005234

George, P. P., Papachristou, N., Belisario, J. M., Wang, W., Wark, P. A., Cotic, Z., . . Car, J. (2014). Online eLearning for undergraduates in health professions: A systematic review of the impact on knowledge, skills, attitudes and satisfaction. Journal of global health, 4(1), 010406-010406. https://doi.org/10.7189/jogh.04.010406

Ghenghesh, P., Croxford, L., Nagaty, K., \& Abdelmageed, S. (2018). Students and Teachers Attitudes and Satisfaction toward E-Learning: A Case Study in Egypt. The Journal of Middle East and North Africa Sciences, 4(1), 1-17. https://doi.org/10.12816/0044059

Hara, N. (2000). Student distress in a web-based distance education course. Information, $\begin{array}{llll}\text { Communication } & \mathcal{E} & \text { Society, } & 3(4),\end{array}$ https://doi.org/10.1080/13691180010002297

Hara, N., \& Kling, R. (2001). Student distress in web-based distance education. Educause Quarterly, 24(3), 68-69.

Haslerud, T., Tulipan, A. J., Gray Jr, R. M., \& Biermann, M. (2017). E-learning for medical imaging specialists: introducing blended learning in a nuclear medicine specialist course. Acta radiologica open, 6(7), 2058460117720858. https://doi.org/10.1177/2058460117720858

Hawkins, B., \& Oblinger, D. (2005). The Myth about E-Learning. Educause Review, 40(4), 14-15.

Hiltz, S. R., \& Turoff, M. (2005). Education goes digital: The evolution of online learning and the revolution in higher education. Communications of the ACM, 48(10), 59-64. https://doi.org/10.1145/1089107.1089139 
Hodges, C., Moore, S., Lockee, B., Trust, T., \& Bond, A. (2020). The difference between emergency remote teaching and online learning. Educause Review, 27.

Hubackova, S. (2015). History and perspectives of elearning. Procedia-Social and Behavioral Sciences, 191, 1187-1190. https://doi.org/10.1016/j.sbspro.2015.04.594

Ilic, D., Hart, W., Fiddes, P., Misso, M., \& Villanueva, E. (2013). Adopting a blended learning approach to teaching evidence based medicine: a mixed methods study. BMC medical education, 13(1), 169. https:// doi.org/10.1186/1472-6920-13-169

Joo, Y. J., Lim, K. Y., \& Kim, E. K. (2011). Online university students' satisfaction and persistence: Examining perceived level of presence, usefulness and ease of use as predictors in a structural model. Computers \& Education, 57(2), 1654-1664. https://doi.org/10.1016/j.compedu.2011.02.008

Khan, B. H. (2005). Managing e-learning: Design, delivery, implementation, and evaluation. London, UK: Idea Group Inc (IGI).

Likert, R. (1932). A technique for the measurement of attitudes. Archives of psychology, 22(140), 55.

Liu, X., Liu, J., \& Zhong, X. (2020). Psychological State of College Students During COVID19 Epidemic (3/10/2020). http://dx.doi.org/10.2139/ssrn.3552814

MOE. (2020). Distance education in Saudi universities complements the educational journey of male and female students. Retrieved from https://www.moe.gov.sa/ar/news/Pages/un-c-2020-75.aspx

Moore, R., Madsen, L. V., \& Trans, M. (2019). Stress Sensitivity and Signs of Anxiety or Depression among First Year Clinical Dental and Medical Students. Open Journal of Medical Psychology, 9(1), 7-20. https://doi.org/10.4236/ojmp.2020.91002

Muilenburg, L. Y., \& Berge, Z. L. (2005). Student barriers to online learning: A factor analytic study. Distance education, 26(1), 29-48. https://doi.org/10.1080/01587910500081269

Ngan, O. M. Y., Tang, T. L. H., Chan, A. K. Y., Chen, D. M., \& Tang, M. K. (2018). Blended learning in anatomy teaching for non-medical students: an innovative approach to the health professions education. Health Professions Education, 4(2), 149-158. https:// doi.org/10.1016/j.hpe.2017.11.001

Nunnally, J. C. (1975). Psychometric theory - 25 years ago and now. Educational Researcher, 4(10), 7-21. https://doi.org/10.3102/0013189x004010007

Odriozola-González, P., Planchuelo-Gómez, Á., Irurtia, M. J., \& de Luis-García, R. (2020). Psychological effects of the COVID-19 outbreak and lockdown among students and workers of a Spanish university. Psychiatry research, 290, 113108. https:// doi.org/10.1016/j.psychres.2020.113108

Pekrun, R. (2006). The control-value theory of achievement emotions: Assumptions, corollaries, and implications for educational research and practice. Educational psychology review, 18(4), 315-341. https:// doi.org/10.1007/s10648-006-9029-9

Perry, R. P., Hladkyj, S., Pekrun, R. H., \& Pelletier, S. T. (2001). Academic control and action control in the achievement of college students: A longitudinal field study. Journal of educational psychology, 93(4), 776. https://doi.org/10.1037/00220663.93.4.776

Perry, R. P., \& Smart, J. C. (1997). Effective teaching in higher education: Research and practice. New York, USA: Agathon Press.

PNU. (2020). College of Health and Rehabilitation Sciences. Retrieved 15/4/2020. Retrieved from https://www.pnu.edu.sa/en/Faculties/HealthRehabilitation/Pages/Home.aspx

Rodríguez-Ardura, I., \& Meseguer-Artola, A. (2016). What leads people to keep on elearning? An empirical analysis of users' experiences and their effects on 
continuance intention. Interactive Learning Environments, 24(6), 1030-1053. https:// doi.org/10.1080/10494820.2014.926275

Saddik, B., Hussein, A., Sharif-Askari, F. S., Kheder, W., Temsah, M.-H., Koutaich, R. A., . . . Hamid, Q. (2020). Increased levels of anxiety among medical and non-medical university students during the COVID-19 pandemic in the United Arab Emirates (13/5/2020). medRxiv. https:// doi.org/10.1101/2020.05.10.20096933

Sajid, M. R., Laheji, A. F., Abothenain, F., Salam, Y., AlJayar, D., \& Obeidat, A. (2016). Can blended learning and the flipped classroom improve student learning and satisfaction in Saudi Arabia? International journal of medical education, 7, 281-285. https://doi.org/10.5116/ijme.57a7.83d4

SPA. (2020, 6/4/2020). Saudi Arabia imposes 24-Hour Curfew Saudi Press Agency. Retrieved from https:// www.spa.gov.sa/viewfullstory.php?lang=en\&newsid=2071013

Spitzer, R. L., Kroenke, K., Williams, J. B., \& Löwe, B. (2006). A brief measure for assessing generalized anxiety disorder: the GAD-7. Archives of internal medicine, 166(10), 1092-1097. https://doi.org/10.1001/archinte.166.10.1092

Uziak, J., Oladiran, M. T., Lorencowicz, E., \& Becker, K. (2018). Students' and instructor's perspective on the use of Blackboard Platform for delivering an engineering course. The Electronic Journal of e-Learning, 16(1), 1.

Warmbrod, J. R. (2014). Reporting and Interpreting Scores Derived from Likert-Type Scales. Journal of Agricultural Education, 55(5), 30-47. https://doi.org/10.5032/jae.2014.05030

Yang, Y., \& Cao, L. (2013). Differential influences of achievement approach goals and intrinsic/extrinsic motivation on help-seeking in e-learning. Knowledge Management \& E-Learning: An International Journal, 5(2), 153-169. https://doi.org/10.34105/j.kmel.2013.05.011

You, J., Kang, M., \& Pahng, P. (2013). Moderating effects of academic emotions between perceived academic control and self-regulated learning in online courses. Paper presented at the E-Learn: World Conference on E-Learning in Corporate, Government, Healthcare, and Higher Education, Las Vegas, NV, USA.

You, J. W., \& Kang, M. (2014). The role of academic emotions in the relationship between perceived academic control and self-regulated learning in online learning. $\begin{array}{lllll}\text { Computers } & \mathcal{E} & \text { Education, }\end{array}$ https://doi.org/10.1016/j.compedu.2014.04.018

Zakaria, N., Jamal, A., Bisht, S., \& Koppel, C. (2013). Embedding a learning management system into an undergraduate medical informatics course in Saudi Arabia: lessons learned. Medicine 2.0, 2(2), e13. https://doi.org/10.2196/med20.2735

Zhai, Y., \& Du, X. (2020). Addressing collegiate mental health amid COVID-19 pandemic. Psychiatry research, 288, 113003. https://doi.org/10.1016/j.psychres.2020.113003

Zimmerman, B. J., \& Martinez-Pons, M. (1988). Construct validation of a strategy model of student self-regulated learning. Journal of educational psychology, 80(3), 284. https:// doi.org/10.1037/0022-0663.80.3.284 